\title{
摩擦性塑性体の吂り線の幾何学
}

\author{
正員山口柏樹*

\section{GEOMETRIES RELATED TO THE SLIP LINES IN THE PLASTIC MATERIAL WITH FRICTIONAL RESISTANCE} \\ By Hakuju Yamaguchi, C.E. Member
}

\begin{abstract}
Synopsis : In the present paper, the geometrical properties of the slip lines in the plastic material with frictional resistance, especially the relations among the lengths measured alon$g$ each side of a small element composed of slip lines are studied. The results herein obtained will be useful for getting the numerical solutions of modified Kötter's equations.

Prandtl's theorem is also presented in the modified form together with the discussions on both equi-pressure theorem and Mikhlin's coordinates.

要 旨 本論文では摩擦性塑性体の过り線の幾何学的性質, 特に方り線で囲まれる微小要素の辺長間 の関係を調べたが，これは拡張された Kötter の方程式の数值解法上有效なものとなろう。

な招Prandtl の定理の修正された形を求め, めわせて等圧定理，Mikhlin の座標の考察を行つた。
\end{abstract}

\section{1. 序論}

前論文 ${ }^{1)}$ で，土のような摩擦抵抗並びに自重を無視でき好材料の塑性平面ヒズミ問題では，'塑性場を特徴づけ る过り線模様の組み立てには，差分的数值解法が汪とんど唯一の方法であることを指摘した。すなわち図一1に

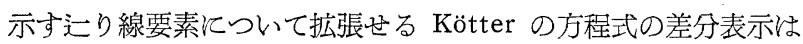

$$
\begin{gathered}
\text { i) } \tau_{B}-\tau_{A}-\left(\tau_{B}+\tau_{A}\right)\left(\theta_{B}-\theta_{A}\right) \mu=r d s_{1} \sin \phi \sin \left(\frac{\theta_{B}+\theta A}{2}-\phi\right) \\
\text { ii) } \tau_{C}-\tau_{D}-\left(\tau_{C}+\tau_{D}\right)\left(\theta_{C}-\theta_{D}\right) \mu=r d s_{1}{ }^{\prime} \sin \phi \sin \left(\frac{\theta_{C}+\theta_{D}}{2}-\phi\right) \\
\text { iii) } \tau_{D}-\tau_{A}+\left(\tau_{D}-\tau_{A}\right)\left(\theta_{D}-\theta_{A}\right) \cdot \mu=r d s_{2} \sin \phi \cos \frac{\theta_{D}+\theta_{A}}{2} \\
\text { iv) } \tau_{C}-\tau_{B}+\left(\tau_{C}+\tau_{B}\right)\left(\theta_{C}-\theta_{B}\right) \mu=r d s_{2}{ }^{\prime} \sin \phi \cos \frac{\theta_{C}+\theta_{B}}{2} \\
\mu=\tan \phi
\end{gathered}
$$

ここでては茫り線上の合セン断応力（粘着力も含めたもので $\tau=c+\sigma \mu$ ) で, $\theta$ は $s_{1}$ 过り線が $x$ 軸となす角 (反 時計周り方向) で， $\phi$ は土のセン断抵抗角であり，rは土の有効単位重量である。

汇り線場の組み立てに和いて, 各点の $\tau$ との両者を求めね佂ならない。この時 $(\mathrm{A})$ 例觉ば $A B$ と $A D$ が, その上の $\theta$ と共に与兄られれば， $\tau_{C}$ と $\theta_{C}$ は前式 ii)，iv）を連立して解けばよい（Riemann の問題または特

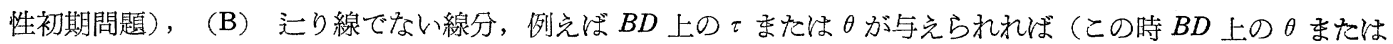
$\tau$ が既知となる) 同じくii), iv) から $\tau_{C}$ と $\theta_{C}$ が求められる (Cauchy の問題)，(C) $A B$ と一曲線例觉ば $A C$ 上の $\theta$ が与えられた時 iv) から $\theta_{C}$ が求まる (混合境界值問題), 江分類されることは明らかである。例兄ば $A B$ 上での $\tau, \theta$ が知られていても ii), iii)，iv）から $C, D$ 亿関する4コの未知量は決定し得ないが，これは过り 線（すなわち特性曲線）の本質上当然のことである。

金属の塑性論飞おいては，(1.1）の右辺が0であるので問題はないが，今の場合 (A) 飞ついて云うとd $\dot{s}_{1}{ }^{\prime}$ ， $d s_{2}{ }^{\prime}$ そのものる未知であることが差分解を複雑ならしめる。このため恃， $d s{ }^{\prime}, d s{ }^{\prime}$ を他の量であらかじめ表 示して招かるばならない。換言すれ杖，差分解を遂行するための準備として，特に过り線の幾何学的性質を多少 明らかとせねばならない。本論文に执いては, これらの関係のほか, 金属の塑性論で知られている Prandt1 の定 
理，Mises の定理，Mikhlinの座標がいかと書き替兄られるかを調べて見たい。

\section{2. 斜交曲線群の線素長}

二次元塑性場では二組の汇り線が互いと $\pi / 2 \pm \phi$ の角度で交攴する斜交曲線網目を形成することは周知である。 ただし二本只上の迄り線が集中するような応力特異点は除外する。この時まず, 図一1の $d s_{1}{ }^{\prime}, d s{ }^{\prime}$ を既知量 $d s_{1}, d s_{2}$ 特よび $\theta$ で表示しよう。ベクトル的に $\overrightarrow{A B}+\overrightarrow{B C}=\vec{A} D+\vec{D} C$ であるからこれを $x y$ 成分と分解すると，

$$
\begin{array}{r}
d s_{1} \cos \frac{\theta_{A}+\theta_{B}}{2}-d s_{2}{ }^{\prime} \sin \left(\frac{\theta_{B}+\theta_{C}}{2}-\phi\right) \\
=d s_{1}{ }^{\prime} \cos \frac{\theta_{r}+\theta_{D}}{2}-d s_{2} \sin \left(\frac{\theta_{A}+\theta_{D}}{2}-\phi\right) \\
d s_{1} \sin \frac{\theta_{A}+\theta_{B}}{2}+d s_{2}{ }^{\prime} \cos \left(\frac{\theta_{B}+\theta_{C}}{2}-\phi\right) \\
=d s_{1}{ }^{\prime} \sin \frac{\theta_{C}+\theta_{D}}{2}+d s_{2} \cos \left(\frac{\theta_{A}+\theta_{D}}{2}-\phi\right)
\end{array}
$$

図-1

であるから, $d s_{1}{ }^{\prime}, d s_{2}{ }^{\prime}$ そついて解けば

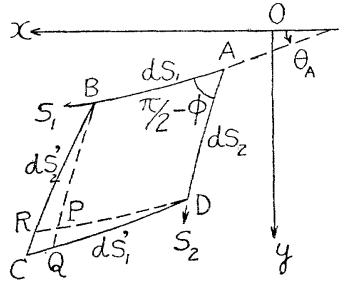

$$
\begin{aligned}
& d s_{1}{ }^{\prime}=\frac{d s_{1} \cos \left(\frac{\theta_{A}-\theta_{C}}{2}+\phi\right)+d s_{2} \sin \left(\frac{\theta_{A}+\theta_{D}}{2}-\frac{\theta_{B}+\theta_{C}}{2}\right)}{\cos \left(\frac{\theta_{B}-\theta_{D}}{2}-\phi\right)} \\
& d s^{\prime}{ }^{\prime}=\frac{d s_{1} \sin \left(\frac{\theta_{C}+\theta_{D}}{2}-\frac{\theta_{A}+\theta_{B}}{2}\right)+d s_{1} \cos \left(\frac{\theta_{A}-\theta_{C}}{2}-\phi\right)}{\cos \left(\frac{\theta_{B}-\theta_{D}}{2}-\phi\right)}
\end{aligned}
$$

上式で微小过り線要素を考える限り, $\left|\theta_{A}-\theta_{C}\right| / 2,\left|\theta_{B}-\theta_{D}\right| / 2 \ll \phi,\left|\left(\theta_{A}+\theta_{D}\right) / 2-\left(\theta_{B}+\theta_{C}\right) / 2\right|, \mid\left(\theta_{A}+\theta_{B}\right) / 2-$ $\left(\theta_{C}+\theta_{D}\right) / 2 \mid \ll 1$ として,

$$
\begin{aligned}
& d s_{1}{ }^{\prime}=d s_{1}+\left(\frac{\theta_{C}+\theta_{D}}{2}-\frac{\theta_{A}+\theta_{B}}{2}\right) \tan \phi d s_{1}+\left(\frac{\theta_{A}+\theta_{D}}{2}-\frac{\theta_{B}+\theta_{C}}{2}\right) \frac{d s_{2}}{\cos \phi}+0\left(\varepsilon^{3}\right) \\
& d s_{2}{ }^{\prime}=d s_{2}+\left(\frac{\theta_{A}+\theta_{D}}{2}-\frac{\theta_{B}+\theta_{C}}{2}\right) \tan \phi d s_{2}+\left(\frac{\theta_{C}+\theta_{D}}{2}-\frac{\theta_{A}+\theta_{B}}{2}\right) \frac{d s_{1}}{\cos \phi}+0\left(\varepsilon^{3}\right)
\end{aligned}
$$

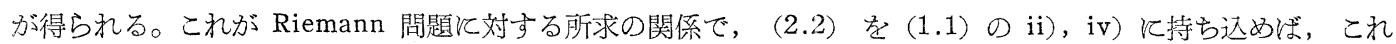
らは $\tau_{C}, \theta_{C}$ 関する連立一次方程式になるから解は容易に得られよう。

自重が無視できる場合は, Hencky の定理が行われる1)から

$$
\theta_{B}-\theta_{A}=\theta_{C}-\theta_{D}=d \theta_{1}, \quad \theta_{D}-\theta_{A}=\theta_{C}-\theta_{B}=d^{2} \theta_{2}
$$

として (2.2) 快

$$
\begin{aligned}
& d s_{1}{ }^{\prime}=d s_{1}\left(1+d \theta_{2} \tan \phi\right)-\frac{d \theta_{1}}{\cos \phi} d s_{2}+O\left(\varepsilon^{3}\right) \\
& d s_{2}{ }^{\prime}=d s_{2}\left(1-d \theta_{1} \tan \phi\right)+\frac{d \theta_{2}}{\cos \phi} d s_{1}+0\left(\varepsilon^{3}\right),
\end{aligned}
$$

さらに $\phi=0$ であれば上式は

$$
d s_{1}{ }^{\prime}=d s_{1}-d \theta_{1} d s_{2}, \quad d s_{2}=d s_{1}+d \theta_{2} d s_{1}
$$

そ帰する(Prandtl)。

(2.2) の右辺各項の幾何学的意味を調べると次のごとくである。今 $B, D$ よりそれぞれ $A D, A B$ に平行な る曲線々素を引いて交点 $P, Q, R$ をつくる (図一1) と, $D Q$ が (2.2) の第一式の右辺 $d s_{1}$ の項を，CQ が $d s_{2}$ の項を表わす。 $B P, R C$ 亿ついてる同様である。

以上述べたととは小さい角 $(\pi / 2-\phi)$ をはささ二辺長が与光られるとした場合であるが，大きい角をはさむ二 辺長が既知であれば，図一1 で $A B, B C$ が与えられたものとして，(2.2) (2.4) 亿応じ

* Hencky Net では例えば $\theta_{1}$ は $s_{2}$ 元り線が基準となる $s_{1}$ 迄り線を切る点での $\theta$ と考えてよいから $\theta_{1}$ 一つの $s_{2}$ 迄り線飞沿つて一定である $\left(\theta_{2}\right.$ 同様)。すなわち $\theta_{1}, \theta_{2}$ は網目の座標に関するパラメータ（独 立变数)と見なしてよい。 


$$
\begin{aligned}
& d s_{1}^{\prime}=d s_{1}+\left(\frac{\theta_{C}+\theta_{D}}{2}-\frac{\theta_{A}+\theta_{B}}{2}\right) \tan \phi \cdot d s_{1}+\left(\frac{\theta_{A}+\theta_{D}}{2}-\frac{\theta_{B}+\theta_{C}}{2}\right) \frac{d s_{2}{ }^{\prime}}{\cos \phi}+0\left(\varepsilon^{3}\right) \\
& d s_{2}=d s_{2}{ }^{\prime}-\left(\frac{\theta_{A}+\theta_{D}}{2}-\frac{\theta_{B}+\theta_{C}}{2}\right) \tan \phi d s_{2}{ }^{\prime}-\left(\frac{\theta_{C}+\theta_{D}}{2}-\frac{\theta_{A}+\theta_{B}}{2}\right) \frac{d s_{1}}{\cos \phi}+0\left(\varepsilon^{3}\right) \\
& d s_{1}{ }^{\prime}=d s_{1}\left(1+d \theta_{2} \tan \phi\right)-\frac{d \theta_{1}}{\operatorname{jos} \phi} d s_{2}{ }^{\prime}+O\left(\varepsilon^{3}\right) \\
& d s_{2}=d s_{2}^{\prime}\left(1+d \theta_{1} \tan \phi\right)-\frac{d \theta_{2}}{\cos \phi} d s_{1}+O\left(\varepsilon^{3}\right)
\end{aligned}
$$

が得られる。

次に図一2で $A B$ 怯与兄られた境界線素（汇り線とは 一致しないるのとする) とし， $\theta$ と同じ意味でその偏角 を $\omega$ とする。ただし $d s_{1}, d s_{2}$ 怔の向きを角 $C$ の大 小飞応じて矢の向きとするが， $A B$ はその方向を指定し ない代り，常に $|\omega| \leqslant \pi / 2$ とする(例兊ば $A B$ が右下り であれば $\omega$ ほ時計周りと測つた角の負值とする)。

この時, 前と同様の取扱いにより, 図一2の(a) (b) 場合に応じて

図-2

(a)

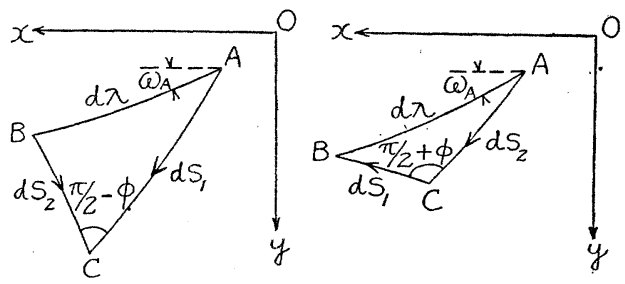

$$
\left.\begin{array}{l}
d s_{1}=\frac{d \lambda}{\cos \left(\frac{\theta_{A}-\theta_{B}}{2}+\phi\right)}\left[\cos \left(\frac{\omega_{A}+\omega_{B}}{2}+\phi-\theta_{B}\right)+\frac{\theta_{C}-\theta_{B}}{2} \sin \left(\frac{\omega_{A}+\omega_{B}}{2}+\phi-\theta_{B}\right)\right] \\
d s_{2}=\frac{d \lambda}{\cos \left(\frac{\theta_{A}-\theta_{B}}{2}+\phi\right)}\left[\sin \left(\theta_{A}-\frac{\omega_{A}+\omega_{B}}{2}\right)+\frac{\theta_{C}-\theta_{A}}{2} \cos \left(\theta_{A}-\frac{\omega_{A}+\omega_{B}}{2}\right)\right] \\
d s_{1}=\frac{d \lambda}{\cos \left(\frac{\theta_{B}-\theta_{A}}{2}+\phi\right)}\left[\cos \left(\frac{\omega_{A}+\omega_{B}}{2}+\phi-\theta_{A}\right)+\frac{\theta_{C}-\theta_{A}}{2} \sin \left(\frac{\omega_{A}+\omega_{B}}{2}+\phi-\theta_{A}\right)\right] \\
d s_{2}=\frac{d \lambda}{\cos \left(\frac{\theta_{B}-\theta_{A}}{2}+\phi\right)}\left[\sin \left(\frac{\omega_{A}+\omega_{B}}{2}-\theta_{B}\right)+\frac{\theta_{B}-\theta_{C}}{2} \cos \left(\frac{\omega_{A}+\omega_{B}}{2}-\theta_{B}\right)\right]
\end{array}\right\}
$$

となる。ここで $O\left(\varepsilon^{3}\right)$ 以省略した。

(2.7) または (2.8) と（1.1）の ii)，iv）式によつて, Cauchy の問題の差分解は, 容易飞行われる。

过り線の正の向き汶する, われわれの約束は相対的のるのであるから，図一2 と逆向き亿矢印を付けてるよ い(このとき，前二式の右辺には僨号が付く）。また図では境界より右下方に，塑性域を組み立てる場合を示した が, 左上方へ組み立てる場合は, $A B$ 汇関寸る $C$ の鏡像的対応点を $C^{\prime}$ とし, 上二式で $C^{\prime} B=d s_{1}, C^{\prime} D=d s_{2}$ と

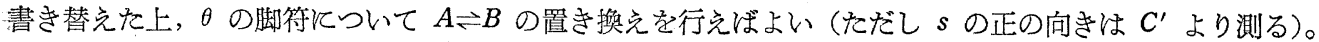

混合型境界值問題飞ついては，一般に上の二つの場合に本筫的飞含まれてしまう。

次簡単な二, 三の例を示とう。

1)放射線と対数螺旋から組み立てられる網目

$$
r=a e^{\theta \tan \phi}
$$

なる対数螺旋と放射動径は $\pi / 2-\phi$ で交叉する Hencky Net であるので, 図一1 で $A B=d s_{1}=d r, A D=$ $\leadsto d \theta / \cos \phi, d \theta_{2}=d \theta, d \theta_{1}=0$ として, (2.4) より

$$
d s_{1}{ }^{\prime}=d r+d r d \theta \tan \phi, \quad d s_{2}{ }^{\prime}=\frac{r d \theta+d r d \theta}{\cos \phi}
$$

これは解析的に得られる結果と一致する。

2) $\phi \neq 0, r=0$ である塑性域内で，一つの司線簇が直線である時，他の沪り線簇の形を決定するとと

求める汇り線場は Hencky Net である。

$s_{1}$ 簇が直線であるとし，これらは平行ではないとする（平行なれば Rankine 域である）。隣接する二本の $s_{1}$ 式り線の交点を $O_{1}$ とし， $O_{1}$ より芒り線て沿つて測つた動徍長を $r$ とすると (2.4)で $d \theta_{1} \equiv 0, d \theta_{2}=d \theta$ として

$$
d s_{1}{ }^{\prime}=d s_{1}(1+d \theta \tan \phi), d s_{2}{ }^{\prime}=d s_{2}+\frac{d \theta}{\cos \phi} d s_{1}
$$


明らか飞, $d s_{1}=d r, d s_{2}=r d \theta / \cos \phi, d s_{2}{ }^{\prime}=(r+d r) d \theta / \cos \phi$ であるから,$d s_{1}{ }^{\prime}=d r+d(d r / d \theta) d \theta$ と共に前式 ヘ入れると

$$
d \theta d\left(\frac{d r}{d \theta}\right)=d r d \theta \tan \phi \quad \therefore r=a e^{\theta \tan \phi}
$$

が得られる。ここで $a$ は，前の交点 $O_{1}$ の位置によるが，全ての $s_{1}$ 达り線が同一点 $O_{1}$ に集末れば， $a$ は共通常 数となつて $s_{1}$ 迄り線は対数螺旋となる。もし相隣る $s_{1}$ 过り線が一点集まらない時は, 個々の微小偏角区画内 で，それぞれ異なる対数螺旋が連続的に連つて $s_{2}$ 迄り線が構成される。

\section{3）不正なる过り線とより求めた応力誤差の構造}

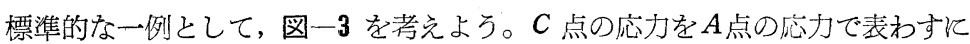
は，正しい迄り線 $A B C$ または $A D C$ 亿沿つて Kötter の式を積分するか, 差分 式を解けぼよいが， $A B C, A D C$ が末知として，乙れを近似迄り線 $A B C, A \overline{D C}$ によつて行つたとする。この場合（1.1）が近似的に成り立つとして i）iv），ii） iii）の二組から $\bar{\tau}_{C}$ を求めると

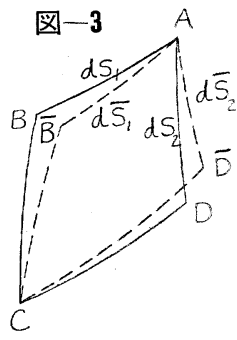

$$
\begin{aligned}
& \bar{\tau}_{C}=\tau_{A}\left\{1+2 \mu\left(2 \tilde{\theta}_{B}-\tilde{\theta}_{A}-\tilde{\theta}_{C}\right)\right\}+r \sin \phi\left(\frac{\tilde{\theta}_{B}+\bar{\theta}_{A}}{2}-\phi\right) d \bar{s}_{1}+r \cos \frac{\tilde{\theta}_{B}+\tilde{\theta}_{C}}{2} d \bar{s}_{2}{ }^{\prime} \\
& \bar{\tau}_{C}=\tau_{A}\left\{1+2 \mu\left(\bar{\theta}_{C}+\tilde{\theta}_{A}-2 \bar{\theta}_{D}\right)\right\}+r \sin \phi\left(\frac{\tilde{\theta}_{C}+\bar{\theta}_{D}}{2}-\phi d \bar{s}_{1}{ }^{\prime}\right)+r \cos \frac{\bar{\theta}_{D}+\bar{\theta}_{A}}{2} d \bar{s}_{2}
\end{aligned}
$$

(2.2) より $d \bar{s} を d s て ゙$ 表わした式は

$$
\begin{aligned}
& d \bar{s}_{1}=d s_{1}\left(1+\frac{\mu \bar{\theta}_{B}-\theta_{B}+\tilde{\theta}_{A}-\theta_{A}}{2}\right)+\frac{d s_{2}{ }^{\prime}}{\cos \phi} \frac{\bar{\theta}_{B}-\theta_{B}+\bar{\theta}_{C}-\theta_{C}}{2} \\
& d \bar{s}_{2}=d s_{2}{ }^{\prime}\left(1+\mu \frac{\theta_{B}-\bar{\theta}_{B}+\theta_{C}-\bar{\theta}_{C}}{2}\right)+\frac{d s_{1}}{\cos \phi} \frac{\theta_{B}-\bar{\theta}_{B}+\theta_{A}-\bar{\theta}_{A}}{2}
\end{aligned}
$$

以下 $(\bar{\theta}-\theta) / 2=\varepsilon$ のごとく記ぜ゙，例总ば

$$
\begin{aligned}
& \sin \left(\frac{\bar{\theta}_{A}+\bar{\theta}_{B}}{2}-\phi\right) \div \sin \left(\frac{\theta_{B}+\theta_{A}}{2}-\phi\right)+\left(\varepsilon_{A}+\varepsilon_{B}\right) \cos \left(\frac{\theta_{B}+\theta_{A}}{2}-\phi\right) \\
& \cos \frac{\bar{\theta}_{B}+\bar{\theta}_{C}}{2} \doteqdot \cos \frac{\theta_{B}+\theta_{C}}{2}-\left(\varepsilon_{B}+\varepsilon_{C}\right) \sin \frac{\theta_{B}+\theta_{C}}{2}
\end{aligned}
$$

のごとくなるから，i）へ ii)， iii）を代入した式を計算し，これらより正しいて (これは i ）で $\bar{\theta} \rightarrow \theta, d \overline{\mathbf{s}} \rightarrow d s$ としたもので求められる）を減ずれば，左周り右周りの場合のC 点の応力愦差として

$$
\begin{aligned}
\bar{\tau}_{C}-\tau(\text { 左周り })=2 & \tau_{A} \mu\left(2 \varepsilon_{B}-\varepsilon_{A}-\varepsilon_{C}\right) \\
& +2 \gamma \mu\left[\left(\varepsilon_{A}+\varepsilon_{B}\right) \sin \left(\frac{\theta_{A}+\theta_{B}}{2}-\phi\right) d s_{1}-\left(\varepsilon_{B}+\varepsilon_{C}\right) \cos \frac{\theta_{C}+\theta_{B}}{2} d s_{2}{ }^{\prime}\right] \\
\bar{\tau}_{C}-\tau(\text { 右周り }=2 & 2 \tau_{A} \mu\left(\varepsilon_{C}+\varepsilon_{A}-2 \varepsilon_{D}\right) \\
& +2 \gamma \mu\left[\left(\varepsilon_{C}+\varepsilon_{D}\right) \sin \left(\frac{\theta_{C}+\theta_{D}}{2}-\phi\right) d s_{1}{ }^{\prime}-\left(\varepsilon_{D}+\varepsilon_{A}\right) \cos \frac{\theta_{D}+\theta_{A}}{2} d s_{2}\right]
\end{aligned}
$$

が得られる。これが求める䛊差構造式であるが, 微小要素について見れば，偏角誤差 右辺で $\theta \rightarrow \bar{\theta}, d s \rightarrow d \bar{s}$ としても誤差の大略の表示式としては, 使用可能であるが, 実際の誤差の見積りには $\varepsilon$ そ

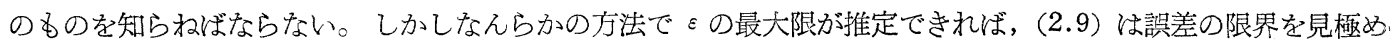
る手段となる。有限領域についても，本方法によれば，ある程度の誤差の推定がなし得るであるう*。

\section{3. 斜交之一り線場が, Hencky Net である条件}

砂質土のごとく，r, $\phi \neq 0$ である材料の过り線場に括いては，次の条件式が別に过り線間に課せられる時にのみ， Hencky Net となる11。すなわち 図一1 とついて

$$
\left.\begin{array}{l}
d s_{1}\left(1-d \theta_{2} \tan \phi\right) \sin \left(\frac{\theta_{A}+\theta_{B}}{2}-\phi\right)+d s_{2}{ }^{\prime}\left(1-d \theta_{1} \tan \phi\right) \cos \frac{\theta_{C}+\theta_{B}}{2} \\
=d s_{1}{ }^{\prime}\left(1+d \theta_{2} \tan \phi\right) \sin \left(\frac{\theta_{C}+\theta_{D}}{2}-\phi\right)+d s_{2}\left(1+d \theta_{1} \tan \phi\right) \cos \frac{\theta_{D}+\theta_{A}}{2}
\end{array}\right\}
$$

* 壁面土圧について近似対数螺線による土圧誤差について見ると，実誤差 $13 \%$ 飞対し，評価誤差は $10 \%$ ， 
この時, Hencky の定理は成り立つから (2.3) より得る関係

$$
\frac{\theta_{A}+\theta_{B}}{2}=\theta_{A}+\frac{d \theta_{1}}{2}, \frac{\theta_{C}+\theta_{B}}{2}=\theta_{B}+\frac{d \theta_{2}}{2}, \frac{\theta_{C}+\theta_{D}}{2}=\theta_{D}+\frac{d \theta_{1}}{2}, \frac{\theta_{D}+\theta_{A}}{2}=\theta_{A}+\frac{d \theta_{2}}{2}
$$

拉よび (2.4) を用いて (3.1) を改めると三次以上の微小量を省略した結果

$$
\begin{gathered}
d s_{1}\left[\left\{\sin \left(\theta_{A}-\phi\right)+\frac{d \theta_{1}}{2} \cos \left(\theta_{A}-\phi\right)\right\}\left(1-d \theta_{2} \tan \phi\right)+\frac{d \theta_{2}}{\cos \phi}\left(\cos \theta_{B}-\frac{d \theta_{2}}{2} \sin \theta_{B}\right)\left(1-d \theta_{1} \tan \phi\right)\right. \\
\left.-\left\{\sin \left(\theta_{D}-\phi\right)+\frac{d \theta_{1}}{2} \cos \left(\theta_{D}-\phi\right)\right\}\left(1+2 d \theta_{2} \tan \phi\right)\right] \\
=d s_{2}\left[\left(\cos \theta_{A}-\frac{d \theta_{1}}{2} \sin \theta_{A}\right)\left(1+d \theta_{1} \tan \phi\right)-\frac{d \theta_{1}}{\cos \phi}\left\{\sin \left(\theta_{D}-\phi\right)+\frac{d \theta_{1}}{2} \cos \left(\theta_{D}-\phi\right)\right\}\left(1+d \theta_{2} \tan \phi\right)\right. \\
\left.-\left(\cos \theta_{B}-\frac{d \theta_{2}}{2} \sin \theta_{B}\right)\left(1+2 d \theta_{1} \tan \phi\right)\right]
\end{gathered}
$$

これは, 相近い引数 $\lambda, \lambda^{\prime}$ 亿関して成り立つ近似式

$$
\cos \lambda-\cos \lambda^{\prime}=\left(\lambda^{\prime}-\lambda\right) \sin \frac{\lambda+\lambda^{\prime}}{2}, \sin \lambda-\sin \lambda^{\prime}=\left(\lambda-\lambda^{\prime}\right) \cos \frac{\lambda+\lambda^{\prime}}{2}
$$

用いて計算すると結局

$$
\tan \phi d \theta_{2} d s_{1} \sin \left(\frac{\theta_{A}+\theta_{D}}{2}-\phi\right)=\tan \phi d \theta_{1} d s_{2} \cos \frac{\theta_{A}+\theta_{B}}{2}
$$

$\phi \neq 0$ てであるから, 上式は

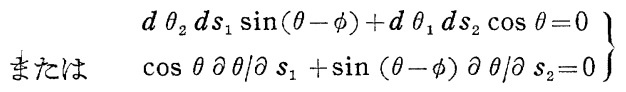

となる。これは (3.1) と等価な条件である。

な和釣合式 $\quad \partial \tau_{s} / \partial s_{1}-2 \tau_{s} \tan \phi \partial \theta / \partial s_{1}=r \sin (\theta-\phi), \partial \tau_{s} / \partial s_{2}+2 \tau_{s} \tan \phi \partial \theta / \partial s_{2}=r \cos \theta$

を用いると，(3.2）火より別な形の等価条件式

$\cos \theta \partial p / \partial s_{1}=\sin (\theta-\phi) \partial p / \partial s_{2}$

が得られる。ここ机 $p \sin \phi+c=\tau_{s}$ なる $p$ は, 过り線上の共役応力である。

一つの过り線簇が直線，例えば $\partial \theta / \partial s_{1}=0$ ならば (3.2) より

$\partial \theta / \partial s_{2}=0$ で他の簇も直線过り線場となり，これは Rankine 芒り線 場に法ならない。したがつて，r, $\phi \neq 0$ である場合は，放射直線群 またはいかなる曲線を包絡線とする直線群も，过り線とはなり得な い。対数螺旋はこの一例である。

\section{Prandtl の定理の拡張}

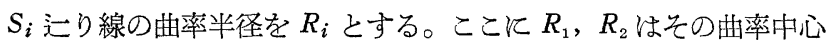

図-4

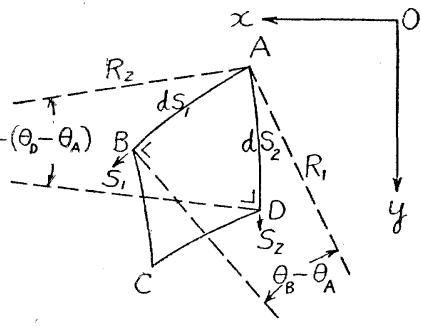

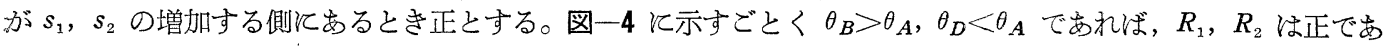
るから $\partial \theta / \partial s_{1}=1 / R_{1}, \partial \theta / \partial s_{2}=-1 / R_{2}$

同図で $C D, B C$ の曲率半径を $R_{1}{ }^{\prime}, R_{2}{ }^{\prime}$ とし，(2.2) を用いると

$$
\begin{aligned}
& R_{1}\left(\theta_{B}-\theta_{A}\right)=d s_{1} \\
& R_{1}{ }^{\prime}\left(\theta_{C}-\theta_{D}\right)=d s_{1}{ }^{\prime}=d s_{1}+\left(\frac{\theta_{C}+\theta_{D}}{2}-\frac{\theta_{A}+\theta_{B}}{2}\right) \tan \phi \cdot d s_{1}+\left(\frac{\theta_{A}+\theta_{D}}{2}-\frac{\theta_{B}+\theta_{C}}{2}\right) \frac{d s_{2}}{\cos \phi} \\
& -R_{2}{ }^{\prime}\left(\theta_{D}-\theta_{A}\right)=d s_{2} \\
& -R_{2}{ }^{\prime}\left(\theta_{C}-\theta_{B}\right)=d s_{2}{ }^{\prime}=d s_{2}+\left(\frac{\theta_{A}+\theta_{D}}{2}-\frac{\theta_{B}+\theta_{C}}{2}\right) \tan \phi d s_{2}+\left(\frac{\theta_{C}+\theta_{D}}{2}-\frac{\theta_{A}+\theta_{B}}{2}\right) \frac{d s_{1}}{\cos \phi}
\end{aligned}
$$

であるから, 記号

$$
\begin{aligned}
& \theta_{B}-\theta_{A}=d \theta_{1}=\frac{\partial \theta}{\partial s_{1}} d s_{1} \equiv \alpha \\
& \theta_{C}-\theta_{D}=d \theta_{1}{ }^{\prime}=\left(\frac{\partial \theta}{\partial s_{1}}+\frac{\partial^{2} \theta}{\partial s_{1} \partial s_{2}} d s_{2}\right) d s_{1} \equiv \alpha^{\prime} \\
& \theta_{D}-\theta_{A}=d \theta_{2}=\frac{\partial \theta}{\partial s_{2}} d s_{2} \equiv \beta \\
& \theta_{C}-\theta_{B}=d \theta^{\prime}{ }_{2}=\left(\frac{\partial \theta}{\partial s_{2}}+\frac{\partial^{2} \theta}{\partial s_{1} \partial s_{2}} d s_{1}\right) d s_{2} \equiv \beta^{\prime}
\end{aligned}
$$


を用いて前 4 式の $\theta$ を $\alpha, \beta$ などで置き替省，さらに

$$
\frac{\alpha+\alpha^{\prime}}{2 \alpha^{\prime}} \div 2 \quad \frac{\beta+\beta^{\prime}}{2 \alpha^{\prime}} \div \frac{\beta}{\alpha} \quad \frac{1}{\alpha^{\prime}}-\frac{1}{\alpha} \div \frac{\alpha-\alpha^{\prime}}{\alpha^{2}}
$$

のごとき近似を用いると， $R^{\prime}=R+d R$ であるから容易に

$$
\begin{aligned}
& d R_{1}=d s_{1}\left(\alpha-\alpha^{\prime}\right) / \alpha^{2}+\tan \phi \cdot \beta d s_{1} / \alpha-d s_{2} / \cos \phi \\
& d R_{2}=d s_{2}\left(\beta^{\prime}-\beta\right) / \beta^{2}+\tan \phi \cdot \alpha d s_{2} / \beta-d s_{1} / \cos \phi
\end{aligned}
$$

が得られ，さらに

$$
\beta d s_{1} / \alpha=-R_{1} d s_{2} / R_{2}, \quad d s_{1}\left(\alpha-\alpha^{\prime}\right) / \alpha^{2}=-R_{1}^{2} d s_{:} \partial^{2} \theta / \partial s_{1} \partial s_{2}
$$

などを考えると前式は

$$
\begin{array}{ll}
s_{2} \text { 飞沿つ } & d R_{1}=-\left(\frac{\partial^{2} \theta}{\partial s_{1} \partial s_{2}} R_{1}{ }^{2}+\tan \phi \frac{R_{1}}{R_{2}}+\frac{1}{\cos \phi}\right) d s_{2} \\
s_{1} \text { 飞沿つ } & d R_{2}=-\left(-\frac{\partial^{2} \theta}{\partial s_{1} \partial s_{2}} R_{2}{ }^{2}+\tan \phi \frac{R_{2}}{R_{1}}+\frac{1}{\cos \phi}\right) d s_{1}
\end{array}
$$

となる。これは $\phi \neq 0$ の時の Prandt1 の定理の拡張されて形式であつて， $\phi=0$ であれば $\partial^{2} \theta / \partial s_{1} \partial s_{2} \equiv 0$ (Hencky Net) であるから (4.1) と共飞 (4.2) は Prandtl の式 (2. 参照) 飞帰することは明白である。

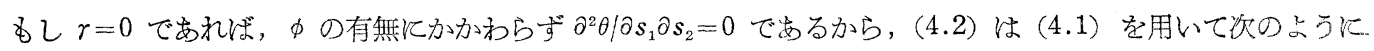
なる。

$$
\begin{gathered}
s_{1} \text { に沿つて }: \quad d R_{2}=-\left(\frac{R_{2}}{R_{1}} \tan \phi+\frac{1}{\cos \phi}\right) d s_{1}=-\left(R_{2} \tan \phi+\frac{R_{1}}{\cos \phi}\right) d \theta_{1} \\
s_{2} \text { 飞沿つて }: d R_{1}=-\left(\frac{R_{1}}{R_{2}} \tan \phi+\frac{1}{\cos \phi}\right) d s_{2}=\left(R_{1} \tan \phi+\frac{R_{2}}{\cos \phi}\right) d \theta_{2}
\end{gathered}
$$

$d \theta_{1}, d \theta_{2}$ は (2.3) の意味で, 座標の独立変数 $\theta_{1}, \theta_{2}$ の微分とすれば，上式から

$$
\frac{\partial^{2} R}{\partial \theta_{1} \partial \theta_{2}}+\mu\left(-\frac{\partial R}{\partial \theta_{1}}+\frac{\partial R}{\partial \theta_{2}}\right)+R=0 \quad\left(R \equiv R_{1}, R_{2}\right)
$$

これは曲率半径関する双曲型の偏微分方程式で, 減言性を考克た電信方程式にほかならない。したがつて境 界の一部で $R_{1}, R_{2}$ が指定される時は，Riemann の積分法が利用できよう2゙。

通常は境界で応力成分が与兄られるが，降伏条件を用いれば，境界での $\theta_{0}$ と応力（例党ばて） は既知量とな る ${ }^{1}$ 。この時境界での $R_{1}, R_{2}$ を求める式導こう。境界の傾きを $\omega$ (図一2 参照) とし, 境界線方向飞距離 $s$ を測ると

$$
\frac{\partial}{\partial s}=\frac{1}{\cos \phi}\left[\cos \left(\theta_{0}-\omega-\phi\right) \frac{\partial}{\partial s_{1}}-\sin \left(\theta_{0}-\omega\right)-\frac{\partial}{\partial s_{2}}\right]
$$

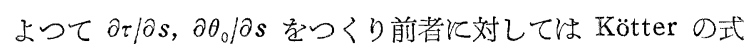

$$
\begin{aligned}
& \frac{\partial \tau}{\partial s_{1}}-2 \mu \tau \frac{\partial \theta}{\partial s_{1}}=r \sin \phi \sin (\theta-\phi) \\
& \frac{\partial \tau}{\partial s_{2}}+2 \mu \tau \frac{\partial \theta}{\partial s_{2}}=r \sin \phi \cos \theta
\end{aligned}
$$

を用い, (4.1) を考光るならば

$$
\begin{aligned}
& \cos \phi \frac{\partial \tau}{\partial s}=2 \mu \tau\left[\frac{\cos \left(\theta_{0}-\omega-\phi\right)}{R_{1}}-\frac{\sin \left(\theta_{0}-\omega\right)}{R_{2}}\right]+r \sin \phi\left[\cos \left(\theta_{0}-\omega-\phi\right) \sin \left(\theta_{0}-\phi\right)-\sin \left(\theta_{0}-\omega\right) \cos \theta_{0}\right] \\
& \cos \phi \frac{\partial \theta_{0}}{\partial s}=\frac{\cos \left(\theta_{0}-\omega-\phi\right)}{R_{1}}+\frac{\sin \left(\theta_{0}-\omega\right)}{R_{2}}
\end{aligned}
$$

これより $R_{1}, R_{2}$ を求めて

$$
\begin{aligned}
\frac{1}{R_{1}}=\frac{1}{4 \mu \tau \cos \left(\theta_{0}-\omega-\phi\right)}\left[\cos \phi \frac{\partial \tau}{\partial s}+2 \tau \sin \phi \frac{\partial \theta_{0}}{\partial s}\right. \\
\left.-r \sin \phi\left\{\cos \left(\theta_{0}-\omega-\phi\right) \sin \left(\theta_{0}-\phi\right)-\cos \theta_{0} \sin \left(\theta_{0}-\omega\right)\right\}\right] \\
\frac{1}{R_{2}}=\frac{1}{4 \mu \tau \sin \left(\theta_{0}-\omega\right)}\left[-\cos \phi \frac{\partial \tau}{\partial s}+2 \tau \sin \phi \frac{\partial \theta_{0}}{\partial s}\right. \\
+r \sin \phi\left\{\cos \left(\theta_{0}-\omega-\phi\right) \sin \left(\theta_{0}-\phi\right)-\cos \theta_{0} \sin \left(\theta_{0}-\omega\right)\right]
\end{aligned}
$$

前述の通り境界上で $\partial \tau / \partial s, \partial \theta_{0} / \partial s$ は既知であるから (4.5) が，そこでの曲率を与兄る式となる。 $\phi=0$ である時は Kötter の式で $2 \mu \tau \rightarrow 2 c, r \sin \phi \rightarrow r, \phi \rightarrow 0, \tau \rightarrow \sigma_{m}$ (平均压力) としたものから出発し（4.5) 
の代りと次式が得られる。

$$
\begin{aligned}
& \frac{1}{R_{1}}=\frac{1}{2 c \cos \left(\theta_{0}-\omega\right)}\left[\frac{\partial}{\partial s}\left(\sigma_{m}+2 c \theta_{0}\right)-r \sin \omega\right] \\
& \frac{1}{R_{2}}=\frac{1}{2 c \sin \left(\theta_{0}-\omega\right)}\left[\frac{\partial}{\partial s}\left(-\sigma_{m}+2 c \theta_{0}\right)+r \sin \omega\right]
\end{aligned}
$$

な括（4.3）を用いて，網目の近似作図法が可能である（差分解の要領は6. で述べる）。Riemann型の問題とつ いてその方法を示すと, 今 図一5 で $A B, A D$ が指定され（簡単のため頂角が $\pi / 2-\phi$ とし特異性はないるのとす る）た時 $C$ の位置を求めるとは，まず

$$
1 / R_{1}=\left(\theta_{B}-\theta_{A}\right) / d s_{1}, d s_{1}=\overline{A B}
$$

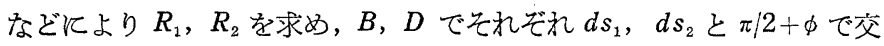
わる二線分 $t_{2}, t_{1}$ を引く。次江 $D, B$ で $t_{1}, t_{2}$ 亿垂線を立て，その上 K $R_{1}, R_{2}$ の存在する方向へ

$$
\begin{aligned}
& O_{1} D=R_{1}-\left(\frac{R_{1}}{R_{2}} \tan \phi+\frac{1}{\cos \phi}\right) d s_{2}, \\
& O_{2} B=R_{2}-\left(\frac{R_{2}}{R_{1}} \tan \phi+\frac{1}{\cos \phi}\right) d s_{1}
\end{aligned}
$$

図-5

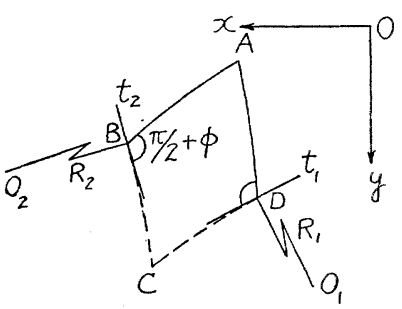

図-6 (c)

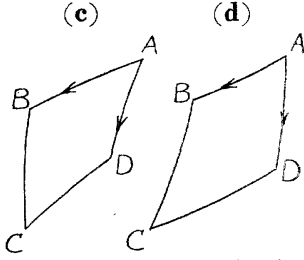

$R_{1}>0, R_{2}<0 \quad R_{1}<0, R_{2}>0$
$R_{1}>0, R_{2}>0$ $d S_{1}^{\prime}<d S_{1}$ $d S_{2}^{\prime}<d S_{2}$

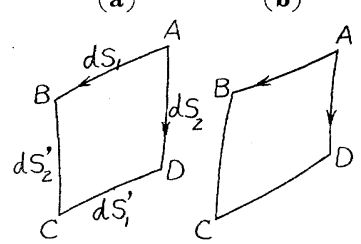

$R_{1}<0, R_{2}<0$

$d S_{1}^{\prime}>d S_{1}$ $d S_{2}^{\prime}>d S_{2}$ $d S_{1}^{\prime}<d S$, $d S_{2}^{\prime}>d S_{2}$ $d S_{1}^{\prime}>d S_{1}$

$d S_{2}^{\prime}<d S_{2}$

図一6 飞曲率半径の正負による要素の基本形を分 類的に示した。

\section{5. 方り線が包絡線をもつ場合}

斜交 Hencky Net $(r=0)$ で，迂り線飞急な折れ曲りがない領域を考光る。この時 $R_{1}, R_{2}$ が同符号であつて， かつ一組の相隣る二本の过り線が合流すれば，他の同簇の过り線も切触的飞合流し，これらは包絡線（いわゆる 自然境界）を形成する。な招 $R_{1}, R_{2}$ が共飞正であれば包絡線は $s_{1}$ または $s_{2}$ の増大する㑡飞現われ，共に負で あれば減少する側飞生ずる。

証明は次の通り。今 $R_{1}, R_{2}$ とも正の時 (4.3) の第二式で $d s_{2}>0$ ならば $d R_{1}<0$ であつて, $d s_{2} \neq 0$ なる限り $s_{2}$ の増すとつれ， $R_{1}$ ほ漸次小さくなりやがて $R_{1} \rightarrow 0$ となる。 $R_{1}, R_{2}<0$ である時 $d s_{2}>0$ ならやはり $d R_{1}<0$ とな るが， $R_{1}$ は負であるから $\left|R_{1}+d R_{1}\right|>\left|R_{1}\right|$ すなわち $\left|R_{1}\left(s_{2}+d s_{2}\right)\right|>\left|R_{1}\left(s_{2}\right)\right|\left(d s_{2}>0\right)$ となつて， $R_{1}$ は $s_{2}$ の減 少するにつれて小さくなる。さて $R_{1}=0$ であれば $(4.1)$ より $d s_{1}=0$, すなわち $s_{2}$ 立り線が 切触的合流を行つ て， $s_{1}$ 过り線はその合流点を超光られない（図一7参照）。以上では，相隣る

図-7 二本の过り線 $\left(s_{2}{ }^{\prime}, s^{\prime \prime}\right)$ のみを考光たが，これら隣接する $s_{2}$ 方り線 $\left(s_{2}{ }^{\prime \prime \prime}\right)$ あ実は始めの合流線沉，さらに合流することが次のようにして知られる。 $s_{2}{ }^{\prime \prime}$ が $s_{2}{ }^{\prime}, s_{2}{ }^{\prime \prime}$ の合流線合流しないとすると, 始奶 $s_{2}{ }^{\prime}, s_{2}{ }^{\prime \prime}$ の合流点 と $s_{2}{ }^{\prime \prime \prime}$ 間の最短距離は 0 でない。よつて合流点から $s_{2}{ }^{\prime \prime \prime}$ へ至る有限長の

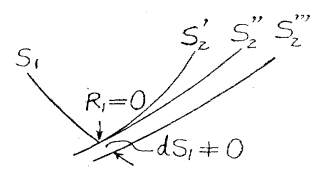

$s_{1}$ 迄り線が存在するばずであるが，これは前述の延長不能 $\left(d s_{1}=0\right)$ の事実と矛盾する。したがつて $s_{2}{ }^{\prime \prime \prime}$ 合流 することとなりこれらは包絡線を形成することが知られる。

一般の場合 $\left(\partial^{2} \theta / \partial s_{1} \partial s_{2} \neq 0\right)$ 飞る， $\partial^{2} \theta / \partial s_{1} \partial s_{2}>0$ の場では，(4.2) の第一式より，同符号の $R_{1}, R_{2}$ 飞対乙 て $d R_{1} \rightarrow 0\left(\therefore d s_{1} \rightarrow 0\right)$ で $s_{2}$ 迄り線簇が包絡線を形成し得る。 $\partial^{2} \theta / \partial s_{1} \partial s_{2}<0$ の場では (4.2) の第二式より $\left.s_{1}\right)$ 簇が包絡線をつくる。これらの例としては，壁面土圧問題の過渡域之り線場があげられ，主働の時は $s_{2} か ゙$ 包絡 線（壁面）を構成乙, 粗度が正なる時は $R_{1}, R_{2}$ とも負, 粗度が負の場合は, $R_{1}, R_{2}$ とも正汶対応している。同 様 $s_{1}$ 簇が包絡線となるのは，受働過渡域で現われる(図一6 参照)。 


\section{5. 斜交 Hencky Net での等角網目}

完全塑性体では迄り線が等角的飞組み立てられる時, 網目の一方の対角線上で圧力 $p$ が一定, 他方の対角線上 では $\theta$ が一定である(von Mises) ${ }^{4)}$ この性質は斜交 Hencky Net でも成り立つが圧力の表示式は修正される。

要素が 図一6の（a）型であるものを考光ると, 一定の偏倚角 $\Delta \theta(>0)$ 亿対し, $\theta_{B}>\theta_{A}, \theta_{C}>\theta_{D}, \theta_{A}>\theta_{D}$, $\theta_{B}>\theta_{C}$ であるから

$$
\theta_{B}-\theta_{A}=\theta_{C}-\theta_{D}=-\left(\theta_{C}-\theta_{B}\right)=-\left(\theta_{D}-\theta_{A}\right)=\Delta \theta
$$

これを(1.1) 飞用い，今の場合 $r=0$ であるから

$$
\begin{aligned}
& \tau_{B}-\tau_{A}-\left(\tau_{B}+\tau_{A}\right) \mu \Delta \theta=0 \\
& \tau_{C}-\tau_{D}-\left(\tau_{C}+\tau_{D}\right) \mu \Delta \theta=0 \\
& \tau_{C}-\tau_{B}-\left(\tau_{C}+\tau_{B}\right) \mu \Delta \theta=0 \\
& \tau_{D}-\tau_{A}-\left(\tau_{D}+\tau_{A}\right) \mu \Delta \theta=0
\end{aligned}
$$

これより

$$
\tau_{B}=\tau_{D}=\frac{\tau_{C}+\tau_{A}}{2} \frac{1-(\mu \Delta \theta)^{2}}{1+(\mu \Delta \theta)^{2}} \div \frac{\tau_{C}+\tau_{A}}{2}\left\{1-2(\mu \Delta \theta)^{2}\right\}
$$

すなわち対角線 $B D$ は $\tau$ 亿関し等圧線となり，前式へ $\tau_{B}=\tau_{D}$ の関係を用いると

$$
\theta_{A}=\theta_{C}=\frac{\theta_{B}+\theta_{D}}{2}
$$

で，AC が等傾線となる。このことは 図一6の（b) 型とついても云えるが，(c)（d）型とついて同様な吟味を 行うと逆に $A C$ 対角線が等圧線, $B D$ 対角線が等傾線となる。

Hencky Net でない時は，もちろん上の式は成り立たないが，斉次一般解に対する応力（サーチャージとよる もの）は，近似的汇（5.1）のごとく表わせるとみてよいと思われる。

\section{Mikhlin の座標の拡張}

直交曲線座標とついて Mikhlin が導入した座標 ${ }^{4}$ は 図-8 (a) そ示すごとく, 頂点 $C$ に抬ける $B C$ の切線 へ， $A$ より下した垂線の足 $P$ 飞関し $, A P=\bar{x}, C P=\bar{y}$ とするる のである。

斜交曲線網目について, Mikhlin の座標に対応するものを新た 飞次のごとく定義しょう。今 $C$ で, $B C, C D$ 亿引いた二切線を $t_{2}$, $t_{1}$ とし， $A$ より $t_{1}$ に平行に引いた線と $t_{2}$ との交点を $P$ とする時

$$
\left.\begin{array}{l}
\bar{x}=A P \\
\bar{y}=C P
\end{array}\right\}
$$

従来の意味の座標 $(x, y)$ と新しい $(\bar{x}, \bar{y})$ の間は

$$
\left.\begin{array}{ll}
\bar{x} \cos \phi=x \cos (\theta-\phi)+y \sin (\theta-\phi) & \text { i) } \\
\bar{y} \cos \phi=-x \sin \theta+y \cos \theta & \text { ii) }
\end{array}\right\}
$$

図-8

(a)

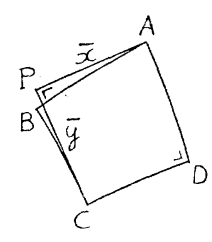

(b)

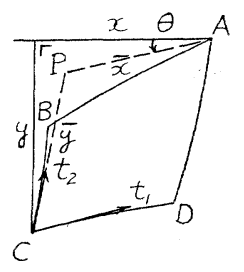

で結ばれる (図一 8 (b) 参照)。 $A B, C D$ を $s_{1}$ 線（过り線とは限らない同様 $A D, B C$ を $s_{2}$ 線とすると， $s_{1}, s_{2}$ 線江沿亏微小長の $x, y$ 成分 $(d x, d y)$ は明らか飞
$s_{1}$ そ沿つて : $d y=\tan \theta \cdot d x$
iii)
$s_{2}$ 江沿つて : $d y=-\cot (\theta-\phi) d x$

を満たす。ii）を $s_{1}$ 上で微分し iii) を用いると

$$
d \bar{y} \cos \phi=(-d x \sin \theta+d y \cos \theta)-(x \cos \theta+y \sin \theta) d \theta=-(x \cos \theta+y \sin \theta) d \theta
$$

しかるに i) ii)より

$\bar{x} \cos \phi=\cos \phi(x \cos \theta+y \sin \theta)-\sin \phi(-x \sin \theta+y \cos \theta)=\cos \phi(x \cos \theta+y \sin \theta)-\bar{y} \sin \phi \cos \phi$

$$
\text { または } \quad x \cos \theta+y \sin \theta=\bar{x}+\bar{y} \sin \phi \quad \text { vi) }
$$

であるから v) は $d \bar{y} \cos \phi=-(\bar{x}+\bar{y} \sin \phi) d \theta$ とかける。同様化 i) $s_{2}$ とで微分し iv $)$, ii $)$, vi）を逐次利 用すると $d \bar{x} \cos \phi=(\bar{y}+\bar{x} \sin \phi) d \theta$ が得られる。すなわちまとめて

$$
\begin{array}{ll}
s_{1} \text { そ沿つて }: & d \bar{y}=-\left(\frac{\bar{x}}{\cos \phi}+\bar{y} \tan \phi\right) d \theta_{1} \\
s_{2} \text { そ沿つて }: & d \bar{x}=\left(\frac{\bar{y}}{\cos \phi}+\bar{x} \tan \phi\right) d \theta_{2}
\end{array}
$$


が得られる。これは形式上 (4.3) と同じだが，(6.3) は一般の斜交網目とついて成立する点が注目される。 Hencky Net であれば $\theta_{1}, \theta_{2}$ を座標の独立変数ととれる〔(2.3) 参照つから (4.4) と同様に

$$
\frac{\partial^{2} \boldsymbol{Z}}{\partial \theta_{1} \partial \theta_{2}}+\mu\left(-\frac{\partial \boldsymbol{Z}}{\partial \theta_{1}}+\frac{\partial \boldsymbol{Z}}{\partial \theta_{2}}\right)+\boldsymbol{Z}=0 \quad(\boldsymbol{Z}=\overline{\boldsymbol{x}}, \overline{\boldsymbol{y}})
$$

が行われる。

Riemann 問題で Hencky Net を対象とする時の網目の作図は (6.3) そより簡単沉行觉る。例えば 図一5 亿 括いてC 点の位置 $\left(x_{C} y_{C}\right)$ は (6.3) を差分化した

$$
\left.\begin{array}{l}
\bar{y}_{C}-\bar{y}_{D}=-\left(\frac{\bar{x}_{C}+\bar{x}_{D}}{2 \cos \phi}+\frac{\bar{y}_{C}+\bar{y}_{D}}{2} \tan \phi\right)\left(\theta_{B}-\theta_{A}\right) \\
\bar{x}_{C}-\bar{x}_{B}=\left(\frac{\bar{y}_{C}+\bar{y}_{B}}{2 \cos \phi}+\frac{\bar{x}_{C}+\bar{x}_{B}}{2} \tan \phi\right)\left(\theta_{D}-\theta_{A}\right)
\end{array}\right\}
$$

より $\bar{x}_{C}, \bar{y}_{C}$ を求め $(6.2)$ を解けばよい。

一般汇り線場では， $\theta_{C}$ も未知だから（6.3）だけではCの位置は決らず，Kötter の式の援用を要するが，この 事情は Cauchy の問題にも現われてくる。すなわち Cauchy 問題で Hencky 場を求める時は $r=0$ を仮想する のだから, Kötter 式

$$
\frac{\partial \tau}{\partial s_{1}}-2 \mu \tau \frac{\partial \theta}{\partial s_{1}}=0 \quad \frac{\partial \tau}{\partial s_{2}}+2 \mu \tau \frac{\partial \theta}{\partial s_{2}}=0
$$

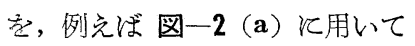

$$
\begin{gathered}
\log \tau_{C}-2 \mu \theta_{C}=\log \tau_{A}-2 \mu \theta_{A} \quad \log \tau_{C}+2 \mu \theta_{C}=\log \tau_{B}+2 \mu \theta_{B} \\
\therefore \theta_{C}=\frac{1}{4 \mu} \log \tau_{B} / \tau_{A}+\frac{1}{2}\left(\theta_{A}+\theta_{B}\right) \ldots \ldots \ldots \ldots \ldots \ldots \ldots \ldots \ldots \ldots \ldots \ldots \ldots \ldots \ldots \ldots \ldots \ldots \ldots \ldots \ldots \ldots
\end{gathered}
$$

で $\theta_{C}$ が知られる。よつて (6.3) から $\bar{x}_{C}, \bar{y}_{C}$ は

$$
\begin{aligned}
& \bar{y}_{C}-\bar{y}_{A}=-\left(\frac{\bar{x}_{C}+\bar{x}_{A}}{2 \cos \phi}+\frac{\bar{y}_{C}+\bar{y}_{A}}{2} \tan \phi\right)\left(\theta_{C}-\theta_{A}\right) \\
& \bar{x}_{C}-\bar{x}_{B}=\left(\frac{\bar{y}_{C}+\bar{y}_{B}}{2 \cos \phi}+\frac{\bar{x}_{C}+\bar{x}_{B}}{2} \tan \phi\right)\left(\theta_{C}-\theta_{B}\right)
\end{aligned}
$$

の根として与えられる。

\section{7. 結 論}

本論文の前半で調べて迄り線素間の公式は, Hencky Net でない一般汇り線場の数值解法上基本的なものであ る。摩擦性材料の塑性場作張された Prandtl, R. von Mises の定理, Mikhlin の座標などは, 一般の过り線 場の決定には不便のようであるが，Hencky Net で近似せしめる時は図式また擞值解法上の手段となり得るこ とが示された。な拉塑性場の特性（例党ば不連続問題など）の理論的研究にね, Prandtl の定理は足掛りとなる であろう。过り線の包絡線関しここ述べたことは, 極く局限されたものというべく, 今後研究の余地がある。

本論文は摩擦を有する材料関する塑性の理論的研究の一部であるが，本研究に関しては東大教授最上博士の 㸸篤な御指導と御討論を仰いだ。ここに厚く感謝の意を表する次第である。

\section{参考文献}

1）山口柏棈：挔張せる Kötter の方程式に関するこ，三の考察（土木学会論文集第 60 号 昭. 34. 1.）

2) 犬井鉄郎: 忘用偏微分方程式論 P.194 (岩波書店)

3) E.G. Thomson: New Method for Construction of Hencky-Prandtl Nets, Jour. of App. Mech. Vol. 24 No. 1

4) R. Hill: The Mathematical Theory of Plasticity (1950) P. 136 149

(昭. 33. 5 . 23) 